\title{
Téoros
}

Revue de recherche en tourisme

\section{Le camping, art de vivre}

\section{Gilles Panné}

Volume 8, numéro 1, mars 1989

\section{France-Québec}

URI : https://id.erudit.org/iderudit/1080352ar

DOI : https://doi.org/10.7202/1080352ar

Aller au sommaire du numéro

\section{Éditeur(s)}

Université du Québec à Montréal

\section{ISSN}

0712-8657 (imprimé)

1923-2705 (numérique)

Découvrir la revue

\section{Citer cet article}

Panné, G. (1989). Le camping, art de vivre. Téoros, 8(1), 16-17.

https://doi.org/10.7202/1080352ar d'utilisation que vous pouvez consulter en ligne.

https://apropos.erudit.org/fr/usagers/politique-dutilisation/ 


\section{Le camping, art de vivre}

Depuis une dizaine d'années, le marché de 1'hôtellerie de plein air est entré, en France, dans une période de profonde mutation. Après avoir connu une forte croissance au rythme de plus de 30000 emplacements par an entre 1975 et 1983, la capacité d'accueil tend, aujourd'hui, à satisfaire la demande, exception faite de la traditionnelle pointe du début août.

Au plan national, l'hôtellerie de plein air ne se développe plus en terme de création de nouveaux terrains mais plutôt en terme de renouvellement des terrains existants. Par ailleurs, la demande de la clientèle s'est transforme: le camping "formule économique" a laissé sa place au camping "art de vivre"

Dorénavant, l'hôtellerie de plein air est vivement sollicitée par des touristes aisés qui sont plus exigeants pour le confort des équipements et pour la qualité de l'accueil. René Ressouches $^{(1)}$, nous a expliqué en détail le bouleversement que subit depuis quelques années l'hôtellerie de plein air, premier hébergement marchand du tourisme. Nous avons souhaité vérifier cette transformation à l'échelle d'une région entière.

Dès 1984, dans le cadre du Réseau d'Observation de l'Activité Touristique, le Comité Régional du Tourisme est chargé par l'État et la Région d'étudier les clientèles touristiques afin de mieux connaittre leurs caracteristiques, leurs motivations et leurs comportements de séjour.

Après l'hôtellerie, les chambres d'hôtes et les gites ruraux, le CRT a poursuivi ses investigations en 1987 et 1988 par le camping.

\section{Une offre substantielle mais inadaptée}

Avec 180 campings et 12200 emplacements, l'hôtellerie de plein air bourguignonne ne représente que $2 \%$ du parc national. Elle constitue toutefois, à égalité avec les 12000 chambres de l'hôtellerie de tourisme traditionnelle, le premier parc d'hébergement marchand.

L'hôtellerie de plein air participe activement à l'économie régionale: plus de 800000 campeurs et 2 millions de nuitées occasionnent près de 130 millions de francs par an sous forme de dépenses courantes.

\footnotetext{
- Gilles Panné est chargé de mission au Comité Régio-
} nal du Tourisme de Bourgogne
Cependant, l'hôtellerie de plein air bourguignonne souffre de maux qui restent pour la plupart très connus des régions rurales:

- une saisonnalité très marquée se traduisant par des taux d'occupation trìs modestes (en 1987, un emplacement sur trois seulement a été occupé pendant la saison, celleci s'étalant en moyenne sur 56 jours) et par une certaine difficulté à capter la clientèle aux marges (printemps, automne), (voir tableau I)

- une relative inadaptation des campings aux nouvelles exigences de confort de la clientèle.

Près de $80 \%$ des campings bourguignons sont classés 1 ou $2 *$ alors que les vacanciers recherchent de plus en plus les 3 et $4^{*}$. Cette constatation est d'ailleurs encore plus dramatique pour le milieu rural hors des grands axes de circulation.

- Une présence très affirmée des collectivités locales dans la gestion des campings qui ne répond pas vraiment aux prérogatives du marketing et de la commercialisation des entreprises touristiques.

A peine $20 \%$ des campings bourguignons bénéficient d'un statut d'exploitation à but

TABLEAU 1

Taux d'occupation des campings de Bourgogne (Saison 1987 - en 5 des emplacements)

\begin{tabular}{|c|c|c|c|c|c|}
\hline \multicolumn{2}{|c|}{ Selon le mois } & \multicolumn{2}{|c|}{ Selon le departement } & \multicolumn{2}{|c|}{ Selon la caltegorie } \\
\hline Juin & 23 & Cote d'Or & 43 & $\Rightarrow$ & 31 \\
\hline Juillet & 58 & Sabone et Loire & 41 & से मे & 33 \\
\hline Août & 59 & Nievre & 34 & & \\
\hline Septembre & 23 & Yonne & 32 & 传台 et से मे मे & 47 \\
\hline Ensemble & 37 & Ensemble & 37 & Ensemble & 37 \\
\hline
\end{tabular}

Source: enquête mensuelle auprès des campings INSEE/CRT/CDT - 1987

TABLEAU 2

Ce camping vous offre-t-il les services que vous attendez?

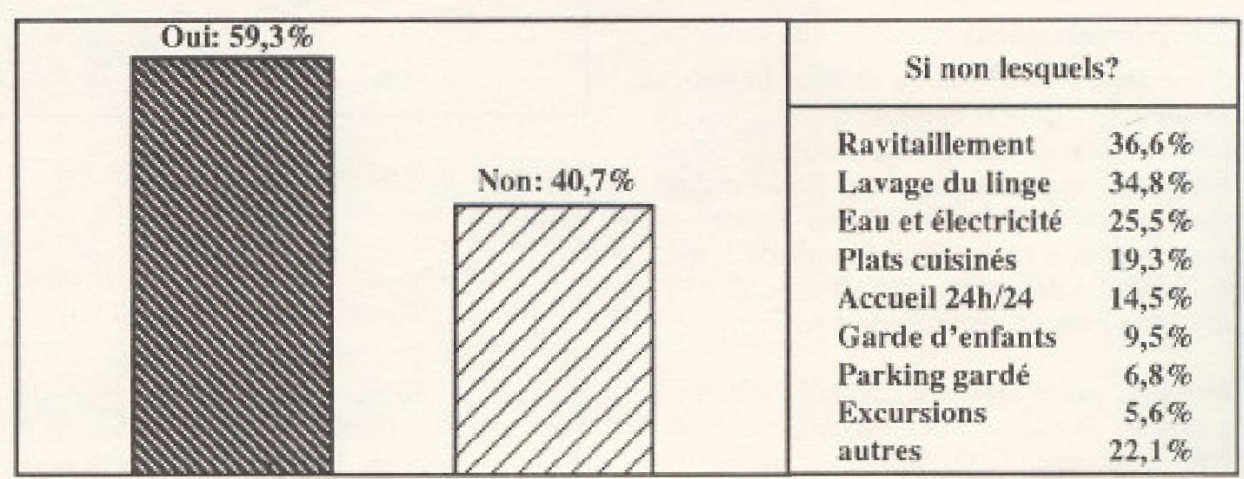


visiter les monuments des environs, en bref pour passer des vacances tranquilles.

- il recherche avant tout un camping avec des sanitaires propres, secondairement un endroit calme avec un bon rapport qualité/prix et privilégie les campings à emplacements bien séparés.

- il ne réserve pas son emplacement à l'avance et se fie aux guides existants, s'il fait son choix avant son départ, ou aux panneaux situés le long des routes, s'il se détermine seulement à son arrivée en Bourgogne. - une fois sur deux, il n'est pas vraiment satisfait des prestations offertes par le camping et accepterait volontiers qu'on pallie notamment le manque d'eau et d'électricité à chaque emplacement et l'absence de lavelinge dans le camping.

- en ce qui concerne les améliorations internes du camping, il insíste surtout sur la qualité des équipements sanitaires et souhaite la mise à disposition d'informations touristiques sur place.

- pour l'environnement immédiat, il aimerait que les efforts portent sur la signalisation routière d'acces au camping, sur la disponibilité d'informations touristiques sur place.

- il ne passe guère plus de 4 ou 5 heures à l'extérieur du camping.

- il est peu dépensier, même s'il sort quelquefois au restaurant, il n'achète guère que des vins et en dose plutôt homéopathique. - il n'hésiterait pas ầ venir hors de la haute saison touristique (printemps, automne), viendrait alors plutôt en caravane et ne serait pas attiré par un séjour à thème précis.

- il renouvellera volontiers son séjour in Bourgogne et certainement à nouveau en camping.

\section{Messieurs les maires, encore un effort!}

Propreté, notamment des sanitaires toute la journée. Animation, c'est-à-dire éviter l'emplacement sec sur un terrain où il n'y a rien à faire, ni pour les adultes, ni pour les enfants. Confort, avec des services recherchés par les campeurs (lave-linge, ravitaillement sur place, eau et électricité à chaque emplacement, garde d'enfants...).

Voici les trois mots-clés qui permettent de définir les nouvelles conditions d'accès des campeurs à l'hôtellerie de plein air bourguignonne. Si l'on se réfere aux études, il semblerait que cela concerne l'ensemble des campings de France.

Les maires qui tiennent la plupart, du temps, les rênes de l'hôtellerie de plein air, en sontils convaincus?

Il est permis de le penser. C'est en tout cas un challenge que joue nombre de petites communes à l'aube du grand marché europeen de $1992 !$.

\section{Note}

(1) René RESSOUCHES, ESpacES No 81, Une nouvelle clientele pour le camping.
TABLEAU 3

Si vous aviez à améliorer

\begin{tabular}{|lr|lr|}
\hline \multicolumn{2}{|c|}{ Lous porteriez vos efforts sur: } & \multicolumn{2}{c|}{$\begin{array}{c}\text { Le confort du camping; } \\
\text { vous porteriez vos efforts sur: }\end{array}$} \\
\hline Du matériel de loisirs à disposition & $31,2 \%$ & La qualité des sanitaires & $0,8 \%$ \\
Information sur services environinants & $30,0 \%$ & Les informations disponibles & $24,5 \%$ \\
Signalisation routière du camping & $28,0 \%$ & La qualité des emplacements & $19,5 \%$ \\
Les jeux d'extérieur & $22,0 \%$ & La propreté du camping & $12,1 \%$ \\
Les routes d'accès & $13,6 \%$ & La paysage & $7,6 \%$ \\
Autres & $1,4 \%$ & & \\
\hline
\end{tabular}

TABLEAU 4

Répartition des campings suivant leur taille (Nombre de terrains en $\%$

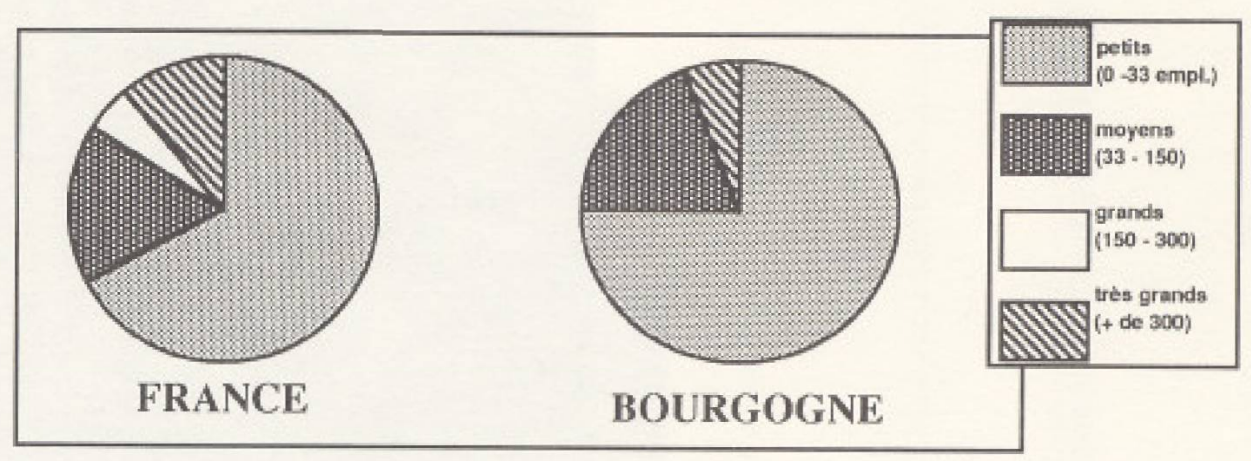

TABLEAU 5

Répartition des campings suivant le statut d"exploitation

(Nombre de terrains en $\%$ )

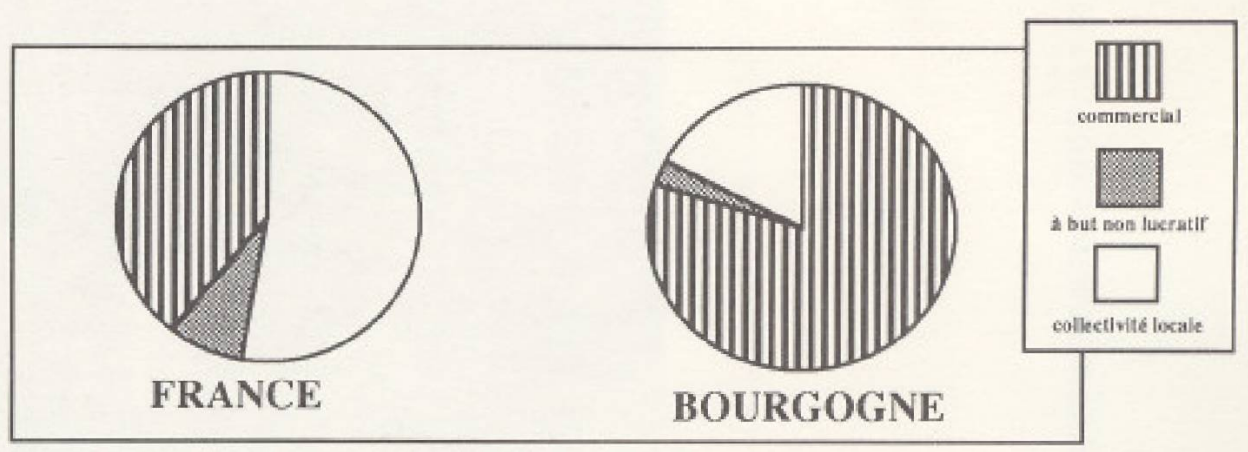

TABLEAU 6

Que pensez-vous de votre camping pour... (Résultats en \&)

\begin{tabular}{|c|c|c|c|c|c|}
\hline Les services & $\begin{array}{c}\text { Pas } \\
\text { satisfaits } \\
\text { du tout }\end{array}$ & $\begin{array}{c}\text { Peu } \\
\text { satisfaits }\end{array}$ & $\begin{array}{c}\text { Moyen- } \\
\text { nement } \\
\text { satisfaits }\end{array}$ & Satisfaits & $\begin{array}{c}\text { Trés } \\
\text { satisfaits }\end{array}$ \\
\hline Laccueil & 3,2 & 6,2 & 15,6 & 36,2 & 38,8 \\
\hline L'organisation & 5,2 & 8,8 & 23,3 & 38.3 & 24,4 \\
\hline Le confort & 2,6 & 10,8 & 31,2 & 35,1 & 20,3 \\
\hline Les sanitaires & 6,0 & 15,3 & 27,3 & 28,1 & 23.3 \\
\hline L'entretien & 2,6 & 6,6 & 20,6 & 40,0 & 30,2 \\
\hline L'alimentation & 13,4 & 14,0 & 29,8 & 13,9 & \\
\hline La tranquilité & 3,6 & 7,6 & 18,6 & 34,6 & 35,6 \\
\hline La sécurité & 6,8 & 8,7 & 23,8 & 35.8 & 24.9 \\
\hline La ganderie & 37,8 & 14,5 & 21,6 & 18,0 & 8,1 \\
\hline La laverie & 16,0 & 17,1 & 26,6 & 24,0 & 13,3 \\
\hline L'épicerie & 23,8 & 15,3 & 25,0 & 23,8 & 12.1 \\
\hline
\end{tabular}

